\title{
Integración de restos arqueológicos en el interior del aparcamiento de Plaza de La Marina. Málaga
}

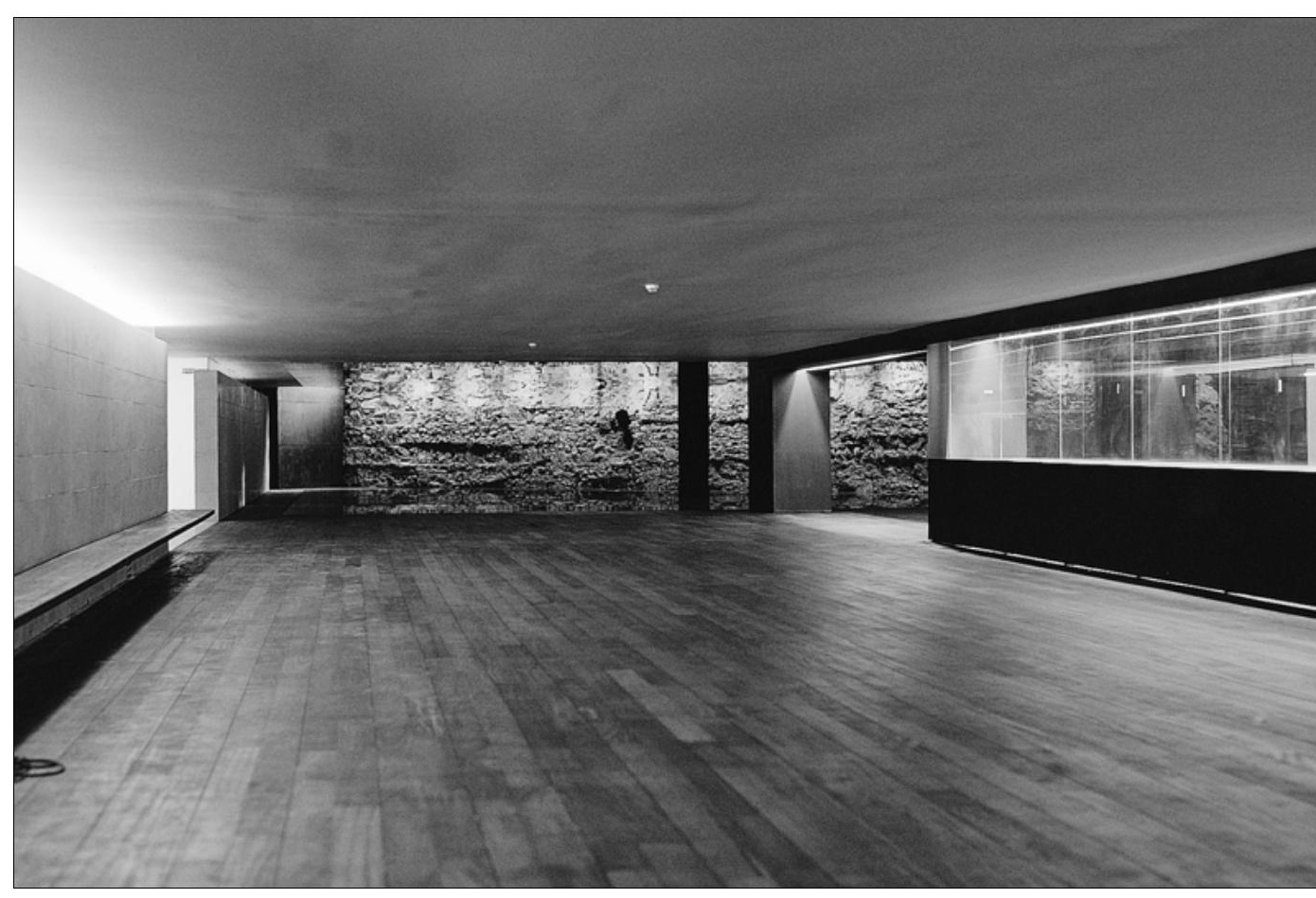

José L. Daroca Bruño Arquitecto

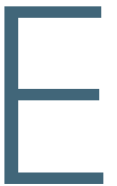

I proyecto de puesta en valor de los restos arqueológicos encontrados en la Plaza de la Marina tiene un interés extraordinario desde la perspectiva de la Difusión. La integración de una huella de la ciudad patrimonial en un entorno aparentemente alejado de los conceptos tradicionales de monumento y entorno -un aparcamiento-, pone de manifiesto la necesidad de hallar ámbitos de encuentro entre el desarrollo urbano y la tutela de su patrimonio.

Aunque el proyecto no ha concluido aún, ya pueden percibirse en él temas que, con toda seguridad, contribuirán a enriquecer el debate establecido en la ciudad entre su pasado, el presente y las perspectivas de futuro. 
Sin embargo, la aparición de cerámica almohade en la parte exterior de la cimentación de uno de los baluartes, hace posible adelantar su construcción, al menos, hasta el final de dicha época o principios de la nazarí siglo XIII.

\section{Sector E}

En el sector opuesto a la muralla nazarí, y próxima a la esquina de la calle Molina Lario, aparece una gran muralla de mampostería, con sillares de cantería de tamaño considerable. Su cara externa forma cierta inclinación, como muro de defensa, y presenta una zarpa en su parte inferior externa; en su remate hacia el interior aparece un rebaje similar a un paso de ronda.

La excavación del interior del muro ha revelado una estratigrafía muy clara, que va desde el s. XVIII hasta el s. XVI, apareciendo material musulmán tan sólo entre las arenas de la escollera, con evidentes sistemas de rodamiento.

Se identifica, por tanto, como una obra portuaria de época moderna, pero su trazado coincide con el que la cartografía histórica indica para la muralla de época musulmana.

\section{DESCRIPCIÓN DE LA PROPUESTA}

La intervención planteada se justifica en sí misma desde el momento en que se asume la situación real de unos restos arqueológicos que se encuentran fuera de contexto. Efectivamente, nos hallamos ante importantes elementos pertenecientes a las que fueran murallas o muros históricos de la ciudad, y que por distintos condicionantes se encuentran hoy en el interior de un aparcamiento subterráneo; por lo tanto, son restos embutidos entre planos horizontales de hormigón, atravesados por soportes verticales.

El objetivo de la propuesta es poner en valor unos restos arqueológicos como parte de la historia de la formación de la ciudad, y no como una mera ruina contemplativa. Para conseguirlo se trata de crear una tensión visual entre ambos lienzos mediante la construcción de elementos o muros paralelos a la acera de la plaza de la Marina, muros que, de un lado, recojan los soportes verticales interiores del aparcamiento, $y$, de otro, proporcionen la máxima visibilidad de los restos arqueológicos al paso del peatón, tanto en su entrada o como en la salida.

Para ello, y adosados al muro perimetral de hormigón paralelo a la acera de la plaza, se reúnen todos aquellos usos que pueden ser compatibles con el propio aparcamiento -aseos, locutorios y cabinas telefónicas, almacenes del aparcamiento, caja de control y cajero automático de tickets ...-, dejando muy permeable la entrada peatonal a través de la rampa.

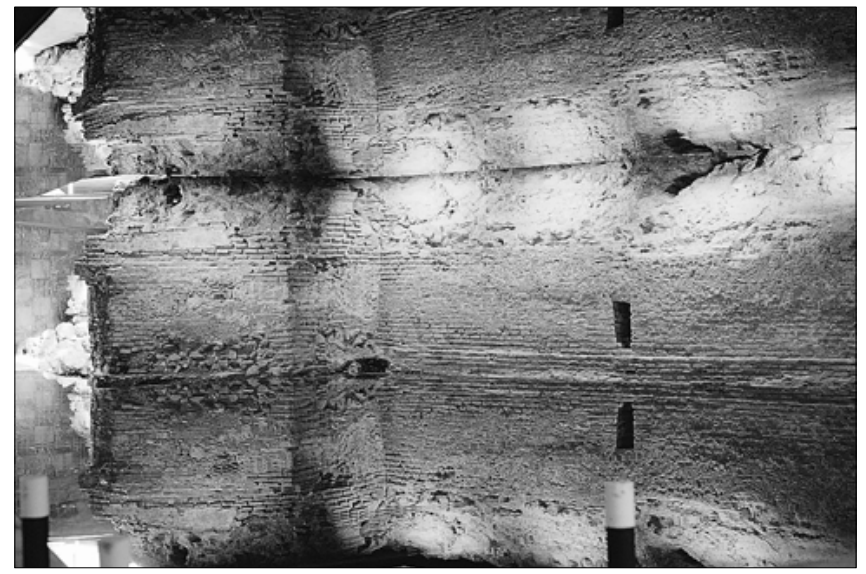

$\leftarrow$
0

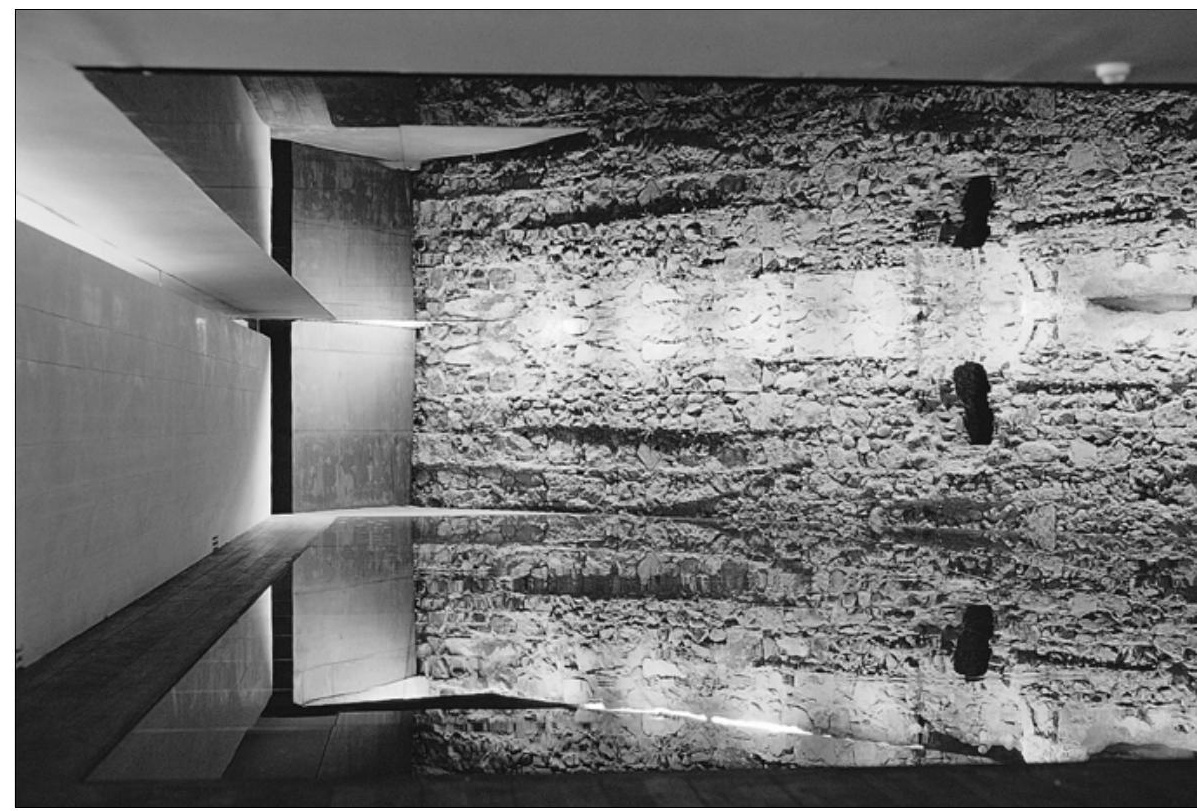

Paralelo a esta crujía edificada, se construye un simbólico muro-vitrina adintelado en su totalidad, el cual, además de incluir los soportes de hormigón existentes, completará la información destinada al público de la historia de la ciudad en ese lugar, por medio de planos, dibujos, audiovisuales, etc.

Delante de este muro-vitrina, y con un esquema volumétrico similar, se sitúa, entre los vehículos y la zona de exposición, otro elemento adintelado paralelo, en principio sin contenidos, y que marque la transición entre áreas de distinto uso.

Como elementos de protección de los lienzos de muralla, está prevista la colocación en el suelo de planos horizontales de vidrio, y que aun siendo transitables, tratará de evitar el acercamiento de peatones y vehículos a los restos arqueológicos. De otro lado, la reflexión de la imagen de los muros en estos planos de vidrio conseguirá realzar y valorar, a través de una adecuada iluminación, los planos verticales de los lienzos.

Como operaciones que deberían realizarse, previas a la intervención, estarían:
3. Vista de la muralla nazarí

4. Muro portuario 
$\longleftarrow$
$\square$

5. Integración de restos del muro portuario del aparcamiento

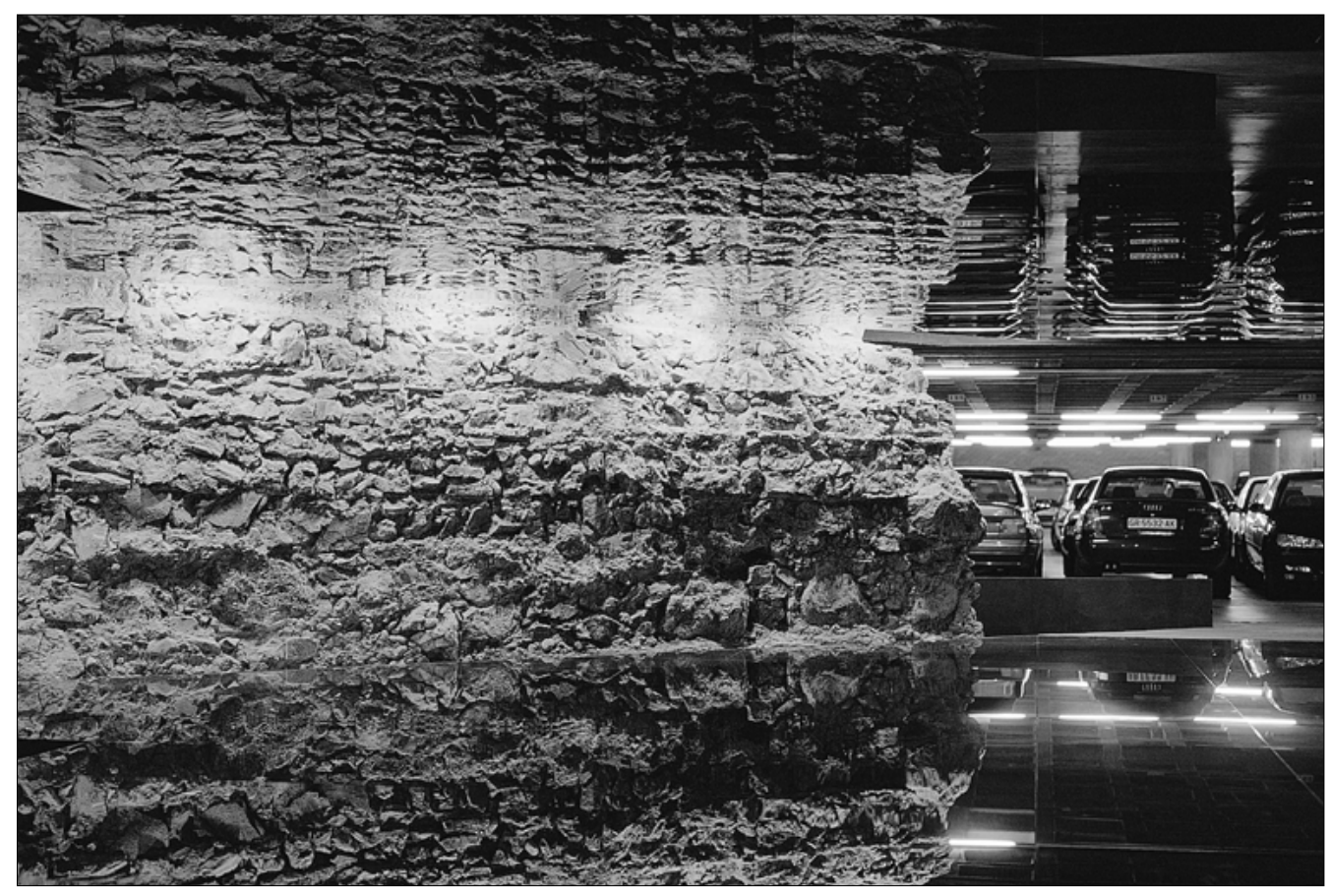

- El tratamiento de los lucernarios existentes en la acera de la plaza de la Marina, entre la calle Marqués de Lario y la de Molina Lario, a través del cerramiento de los huecos existentes sobre ambos lienzos con un material traslúcido y resistente, el cual evite los problemas de penetración de agua de lluvia y de los vertidos de basura.

- La demolición de los muros de fábrica de ladrillo y tabiquerías existentes en el área de intervención, hasta dejar limpia de elementos la zona del proyecto.

- La apertura de la escalera de salida peatonal del aparcamiento en la esquina de la calle Molina Lario, hoy clausurada.

\section{Bibliografía}

ACIÉN, MANUEL: Informe arqueológico de la Plaza de la Marina. SALMERÓN, PEDRO: Informe técnico de la Plaza de la Marina.

\section{Ficha técnica}

Fecha del proyecto: Febrero de 1995

Fecha finalización de las obras: Octubre de 1997

Arquitecto: José L. Daroca Bruño

Aparejador: Roberto Alés Méndez
Empresa Constructora: Construcciones $92-\mathrm{I}^{\mathrm{a}}$ faseC.U.T.E.S.A. $-2^{\mathrm{a}}$ fase-

Promotor: Consejería de Cultura

Dirección General de Bienes Culturales

Instituto Andaluz del Patrimonio Histórico

Delegación Provincial de Málaga (exposición)

Presupuesto de ejecución material: 62.834.034.- ptas. 